\title{
Restructuring an Undergraduate Database Management Course for Business Students
}

\author{
Mali Senapathi \\ Auckland University of Technology, New Zealand.
}

mali.senapathi@aut.ac.nz

\begin{abstract}
An introductory undergraduate database management course is quite common in the undergraduate IS/IT (Information Systems/Information Technology) curriculum. This paper describes the restructuring of such a course from a dominantly technical focus to having a much broader and more integrated approach within the Bachelor of Business (IT Major-Information Technology Major) degree programme at the Auckland University of Technology, New Zealand. The course philosophy and guiding principles underlying the redesign are also discussed. The aims were to restructure the course to be in line with the graduate profile of the IT Major within the degree programme and to improve student performance. Results collected over a period of 5 semesters (during and after the restructuring) indicates that student performance improved significantly during this period.
\end{abstract}

Keywords: IT Major, database, business

\section{Introduction}

Educators are challenged to maintain the currency and relevance of IT (information technology) education, due to the dynamic nature of the information systems profession (Cappel, 2001-2002). One of the important functions of educators is to continually include contemporary topics and technologies in the curriculum and put the students on the forefront of new and leading edge technologies. This will enable our students to fit into the workplace much easier and faster. A number of studies have been conducted to identify the skills that are most sought by the industry (Cappel, 2001-2002; Lee, Trauth \& Farwell, 1995). While these studies help us to understand the industry's needs and perceptions, IT education in universities is usually driven by the philosophical guidelines on which the curricula for different programmes are based, and is often tailored to meet the demands of the local IT scene.

According to Robbert (2000), data management is a crucial issue in today's industry. Computer and IS (information systems) departments in universities should be sensitive to industry's data processing needs (Saiedian \& Farhat, 1991). Database education has reached a point where there is a strong base for teaching both theory and practical side to the use of database management systems (Dietrich \& Urban, 1996). The industry perceives data modelling and SQL (Structured

Material published as part of this journal, either on-line or in print, is copyrighted by Informing Science. Permission to make digital or paper copy of part or all of these works for personal or classroom use is granted without fee provided that the copies are not made or distributed for profit or commercial advantage AND that copies 1) bear this notice in full and 2) give the full citation on the first page. It is permissible to abstract these works so long as credit is given. To copy in all other cases or to republish or to post on a server or to redistribute to lists requires specific permission from the publisher at Publisher@InformingScience.org
Query Language) skills as the most important technical skills that should be possessed by IT graduates (Cappel, 2001-2002). In New Zealand, an introductory database management course is very popular in the undergraduate IS/IT curriculum. According to the NACCQ (National Advisory Committee on Computing Qualifica- 
tions) professional development group (Clear, 1998), a graduate in the Analyst/Programmer generic job stream should acquire a high level of data management and design skills.

There are various approaches to teaching a database management course in an undergraduate IS/IT (Information Systems/Information Technology) curriculum. Saiedian (1992) describes a project-intensive course, where the theoretical concepts are presented in the classroom and students work in teams to implement a database application in six different phases. Students also have the option to choose a real world project. Robbert (2000) describes a methodology that aims to strike a balance between theoretical database knowledge and the practical experience required to handle real time problems.

While most universities that offer database courses in their IT curriculum have similar structure and audience, little consensus exists on the content which has changed radically and more rapidly in the last decade (Springsteel, Robbert \& Ricardo, 2000). Most of these courses have not considered the inclusion of current database technologies such as the use of the WWW and the growth of e-commerce (Springsteel et al., 2000).

As an integral component of the IT curriculum, database courses should undergo continuous refinement to be in pace with the currency and relevance of IT education. The paper describes the restructuring of an undergraduate database course to be in line with the graduate profile distinctions of the IT Major within the university's Bachelor of Business curriculum. The course aim, structure and assessment requirements, both prior to and after the restructuring are described. The teaching and learning approaches used to improve student performance are discussed along with supporting statistical data. The paper concludes with a brief summary of reflections.

\section{The Course -Background and Context}

Information technology is one of the majors available under the Bachelor of Business (BBus)- a broad based business education programme designed to provide a broad understanding of business through an interdisciplinary curriculum, and the specialist skills needed for a professional career (AUT, 2003). The undergraduate programme requires a minimum of 360 points( equivalent to a three-year full-time study), which includes 210 points of integrated courses, 90 points from a chosen major and the remaining 60 points from either elective papers or courses from another major(AUT, 2003). Students choose from a set of ten majors according to their individual career aspirations in

Table 1. Overview of the IT Major

\begin{tabular}{|c|c|}
\hline $\begin{array}{l}\text { Integrated Studies: } \\
\text { Core papers } \mathbf{1 2 0} \text { points } \\
\text { The environment of Business } \\
\text { Business Information Management } \\
\text { Globalisation and Business Enterprise } \\
\text { Managing Business Relationships } \\
\text { Professional studies } \\
\text { Core papers } 90 \text { points } \\
\text { Ethics } \\
\text { Business Development project } \\
\text { Cooperative Education }\end{array}$ & $\begin{array}{l}\text { IT Major } 9 \text { points } \\
\text { Level } 6 \\
\text { Information Engineering } \\
\text { Ebusiness IT infrastructure } \\
\text { Management of the IS Development Process } \\
\text { Level } 7 \\
\text { Strategic data Management Architectures } \\
\text { Human Computer Interaction } \\
\text { Intelligent Business Systems }\end{array}$ \\
\hline Elective Papers & 60 points \\
\hline
\end{tabular}


their preferred area of business such as IT, Marketing, Accounting, Management and eBusiness. An overview of the IT Major in the context of a full Business degree is given in Table 1.

The philosophy that underlies the IT Major within the Bachelor of Business programme at AUT is expressed through the graduate profile of the Major. The IT Major resembles the ACM (IS 2002) curriculum, designed to provide a much broader and an integrated focus within the Bachelor of Business programme. It is designed as a companion to another business related major and does not penetrate deeply into the design and implementation aspects of information systems (Clear, 2000).While intellectual capabilities such as teamwork, time management, report writing, analysing and evaluating information are addressed in the integrated core papers, IT skills are addressed through the six professional papers within the IT Major, the cooperative education experience and the wide range of tools and IT applications addressed throughout the programme(Dougherty et al., 2003); (see Table 1). Students who graduate with the IT Major qualify for business-oriented careers, which may involve a considerable IT dimension (Clear, 2001).

The university strictly complies with the New Zealand educational standard of quality control called 'Moderation'. Moderation is defined as the

"process by which the teaching team keeps a check on its assessment programme and the instruments used to ensure validity in the assessment process and consistency of standards achieved" (AUT, 2001).

Every course undergoes two stages of moderation,

1) pre-assessment moderation: which ensures that each assessment

a. complies with the course learning outcomes,

b. submission deadlines are realistic and achievable for students, and

c. have valid mark distributions.

2) post-assessment moderation: where lecturers teaching on the course meet to

a. discuss any foreseen issues that may have emerged from the assessment,

b. discuss sample scripts from the high, middle and the low mark grades, and

c. ensure consistency in marking.

All courses are also selected for external moderation on a regular basis. While internal moderations are mostly carried out by qualified colleagues within the faculty, external moderations are carried out by qualified staff outside the university.

\section{The Course - Prior to Restructuring}

The course chosen for this study is Strategic Data Management Architectures and is offered at level 7 ( $3^{\text {rd }}$ year of the undergraduate programme) on the Bachelor of Business (IT Major), and constitutes 15 points (150 hours of class contact and independent student learning). An introductory Systems Analysis and Design course called Information Engineering (offered at level 6, $2^{\text {nd }}$ year of the undergraduate programme), is a pre-requisite for the course. The database course has existed on the IT curriculum for almost a decade and is consistently endorsed by students as very practical, useful and relevant to the industry. The main objectives of the course were to 1) enable students to develop an in-depth knowledge of the key concepts and techniques required for the management of data in organizations, 2) provide an understanding of the important issues of Data Base Management Systems, and 3) a sense of the potential of the technology and its impact on business through the design and implementation of small business database systems.

Prior to the 2000-2001 academic years, the course had a dominant focus on the technical aspects of database design and implementation. The learning outcomes and the assessment structure for 
the course that was used in the year 1999 are given in Figures 1 and 2. Each of the assignment's requirements is discussed in the next section.

- Apply data analysis methods to solve a design problem.

- Use a data manipulation language to retrieve data from a relational database.

- Use their knowledge of databases to critically assess a commercial database operation.

- Work within a team environment to design and build a small database system.

- Understand methods of measuring and improving database performance.

- Discuss future trends in database direction.

\begin{tabular}{||l|r|r||}
\hline \multicolumn{1}{|c|}{ Assessment } & $\%$ Weight & $\begin{array}{c}\text { Pass } \\
\text { Min. } \\
\text { Level }\end{array}$ \\
\hline $\begin{array}{l}\text { Assignment } \\
\text { (individual) }\end{array}$ & $25 \%$ & $45 \%$ \\
\hline Project (group) & $45 \%$ & $45 \%$ \\
\hline $\begin{array}{l}\text { Final } \\
\text { examination } \\
\text { (individual) }\end{array}$ & $30 \%$ & $50 \%$ \\
\hline
\end{tabular}

Figure 2: Assessment structure, Semester 2, 1999

Figure 1: Learning outcomes, Semester 2, 1999

\section{Assignment Requirements}

1) The requirements of the individual assignment were to

- Part a-interpret the given schema for a business system and to correct errors and omissions from the system's Entity Relationship Diagram(ERD)

- Part b-create a set of SQL data retrieval queries to satisfy the given business requirements

- Part c-make changes to the database design according to a given set of additional requirements and

- Part d-write a report that discussed and compared key features of two other multi-user databases to the Oracle product.

2) The database project required students to

- Part a-design an ERD to meet the business needs of an interview based scenario

- Part b-design and implement this ERD on a relational database

- Part c-build a front end application using Oracle Forms that does a business task for the system and

- Part d-write a report on the investigation of concurrency control in the form created in part C.

Parts ' $a$ ' and ' $b$ ' of the database project assignment involved part group work (maximum of 4 in a group), while parts 'c' and 'd' were individual components.

3) The third and final assessment, the closed book exam required a clear understanding and application of the conceptual topics covered in the class. 


\section{Issues Encountered}

The pre-requisite for the database course, Information Engineering, a level 6 paper (see Table 1), emphasizes the formulation of business requirements using data and process modelling, and is designed to incorporate all phases of the Systems Development Life Cycle. Therefore, rather than re-emphasizing the modelling aspects, the database course focused mainly on the design and implementation phases, in addition to providing an overview of important conceptual topics in database systems. The major issues that were encountered prior to the restructuring are discussed below.

In order to successfully complete part (b) of the first individual assignment, an in-depth knowledge of SQL was required (starting from basic SELECT statement to advanced concepts such as co-related sub queries and outer-joins). While, technical skills such as design of complex SQL queries has merit, a large number of students found it difficult to be able to independently create the complex queries that were required for the assignment.

The database project required students to work in groups of 3-4 at the design level. The subsequent work of implementation was done as individuals, although it was still necessary to liaison with the rest of the team. Near the end of the semester, students continually complained that the part group work was difficult to manage and co-ordinate. It was also harder to moderate a large project, which involved part group and part individual work. Only a small percentage of the students managed to successfully complete and score higher grades in the course. The pass rates in the course were considerably lower than other courses on the IT Major.

All courses on the Business undergraduate programme run for 13 weeks, and the final examinations commence from week 14. Since the last phase of the database project assignment (application development) was due in week 13, there was not enough study time available for students to prepare for their final exams. In the module evaluations conducted at the end of each semester, students consistently complained that they did not have enough time to prepare for the final written exam.

Students on the IT Major come with varying levels of IT background and experience. Often they have different expectations from the courses on the IT major. Some of our initial concerns were "to what depth should SQL be taught to business students?" and similar to those raised by Springsteel et al., 2000, "What do we expect the student to be able to do as a result of passing this course?" The challenge was to restructure the course not only to be line with the IT Major's graduate profile, but also to maintain the currency and relevance of database education. The overall aim was to give students a wide perspective of data management to comprehend fully the role of databases in organizations.

\section{The Restructuring}

Since the year 2000, the course has been continually reviewed to implement gradual and phased changes. Extensive feedback was sought from industry experts and visiting faculty from other universities. Most of these people also taught on the course for 1-2 semesters. The restructuring involved giving the course the business and management focus it needed to have, to be in line with the graduate profile of the Bachelor of Business (IT) programme. It aimed at providing a much broader perspective of data management, to be able to comprehend the role of databases in organizations. Figure 3 provides an outline of the topics covered in the course in Semester 1, 2003. It should be noted that the main aim of the course is to provide a broad coverage of database concepts with an emphasis on the critical importance of data and database management in managing data as a corporate asset. It does not aim to provide an in-depth coverage from the point of view of the database designer, application programmer or the DBMS (Data Base Management System) implementer. 


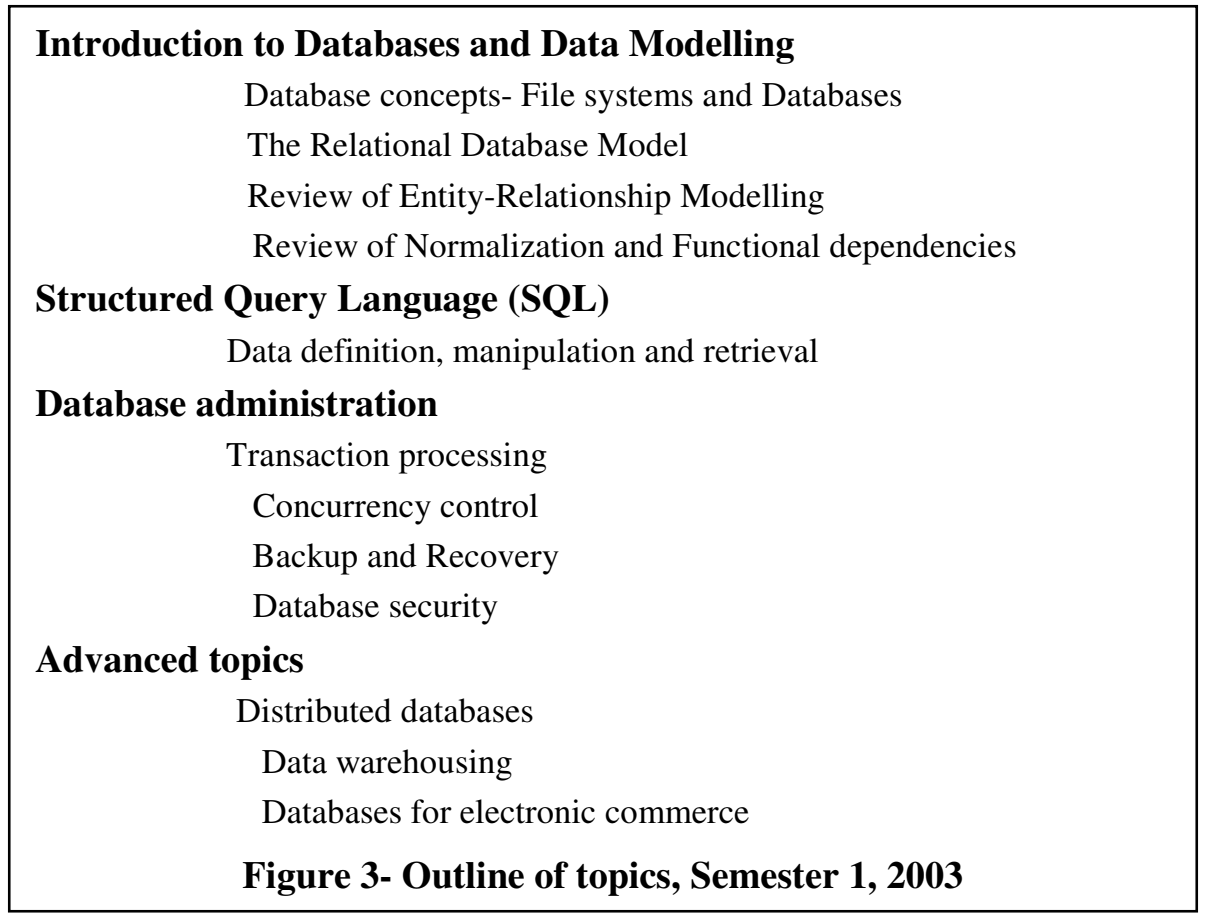

As before the course is taught as a combination of formal lectures and informal tutorial sessions where ORACLE ${ }^{\mathrm{TM}}$ is used as the platform to teach database concepts. Student learning is enforced by applying the theory to practical examples and case studies. The coverage of SQL(Structured Query Language) is reduced to a moderate level and is limited to the use of SQL for elementary functions such as: creating and filling a database, retrieving and sorting data, grouping data and reporting from it, and use of simple joins (equi-join and natural join) for comprehensive data analysis. An overview of SQL commands for security, transaction and integrity management is also included. Students get practical experience as well as theory in the design and implementation of small business database systems. Operational aspects such as security, backup and recovery, concurrency control are also included. Additional specific topics discussed include distributed database systems, databases for electronic commerce, and data warehousing. Since teamwork is addressed in the core integrated papers and most of the other courses on the IT Major, it was decided to remove the part group component from the assignment. The new learning outcomes as they appear in the course outline of Semester 1, 2003 are shown in Figure 4.

- understand relational theory as the basis for relational database management systems;

- be able to perform basic relational data modelling, database design, and database implementation;

- be able to use SQL for database query and other operations;

- analyze business requirements and produce a viable model and implementation of a database to meet such requirements

- understand the role of database management systems in resolving users' needs for information and their place in the information provision environment;

- Understand the concepts of database administration;

- Understand the main concepts and the various architectures of a data warehouse;

- Understand electronic commerce and its effect on the new economy;

Figure 4: Learning outcomes, Semester 1, 2003 


\section{Assignment Requirements-after restructuring}

The new assessment structure is shown in Figure 5. The course itself is now taught in phases, to match the submission requirements of the new assessment structure.

Students also get feedback on their work in individual parts, and they are required to make the necessary corrections/modifications before proceeding to the next phase. Students have consistently and strongly endorsed the staged assessment as an excellent method to plan and organise their course work, since its implementation in 2001. The details of the assessments are given below:

The individual database project is divided into the following four phases

- Phase 1-ERD design to meet the business needs for a given business case,

- Phase 2-database design and implementation,

- $\quad$ Phase 3-design of SQL queries to meet the business tasks for the given case and

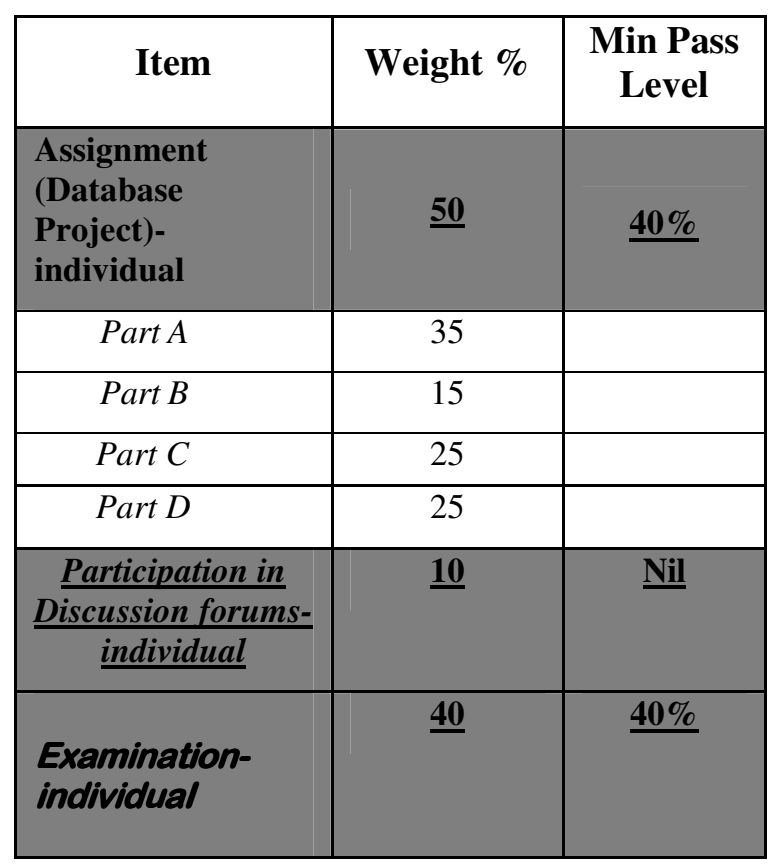

Figure 5. New Assignment Structure

- Phase 4-application development using Oracle Developer tools.

In phase 1, which is allocated 4 weeks, students design an ERD to meet the business needs of a business case. The preliminary documentation of the analysis of the business and data needs for this business is also provided. The technical deliverables due at the end of this phase include: an ERD with identification of attributes for each entity and all primary and foreign keys (drawn using a CASE tool); a list of business rules to demonstrate the reasoning behind each decision; optionality and cardinality based on the derived business rules. Students receive feedback on these deliverables before they start work on the second phase. The feedback is based on the consistency of the derived business rules and the ERD.

In phase 2, students design the structure of the tables with consideration of implementation of the entity model on a relational database using ORACLE ${ }^{\mathrm{TM}}$. However, they are required to make modifications to their ERDs based on the individual feedback they receive on their work in phase 1. At the end of this phase 2, students are required to a)submit table creation scripts, which include all appropriate constraints such as primary key, foreign keys, and check statements; b)documentation of all changes made to the design (ERD) with reasons; and c)sample of realistic data inserted into each table.

Phase 3 involves identification and documentation of data retrieval requirements that would be needed by the business. Instead of designing queries to suit a set of given requirements, students apply their SQL knowledge by designing their own queries to retrieve information meaningful to the business. Specific deliverables of this phase include design of SQL queries, which should incorporate features such as joins, set operators, GROUP BY, HAVING clause and use of aggregate and calculated functions. 
Phase 4 is application development using Oracle developer tools. There are 3 and a half weeks allocated for this phase, at the end which students build and document for the justification and identification of a business need for 1)the creation of an Oracle Forms database application and 2) creation of two data retrieval screens (a group report and a master-detail report) using Oracle Reports. For each report, justification of a business need along with identification of two potential users of this application is also required.

\section{Discussion}

According to the Bachelor of Business assessment policy, the grading scheme we use for this course is as follows: A+(90-100), A (85-89), A- (80-84), B+(75-79), B (70-74), B- (65-69), C+(60-64), C (55-59), C- (50-54) and D (0-49), where D is the fail grade. Since the introduction of the new assessment structure in 2001, student performance was observed to improve significantly in the database project assessment. This is evident from the larger number of A's and B's in the assignment as shown in Figures 6a-6c below (percentage of students who enrolled for the course vs. grades, Please Note: the data includes only student numbers who completed the course). Each grade includes all the ranges under its band, for example, grade $\mathrm{A}$ on the graph includes all spreads in the $\mathrm{A}$ range- $\mathrm{A}+, \mathrm{A}$, and $\mathrm{A}-, \mathrm{B}$ includes $\mathrm{B}+, \mathrm{B}$ and $\mathrm{B}-$ and so on. However, the student performance in the written exam was still a concern, as can be observed by the larger number of C's and D's.

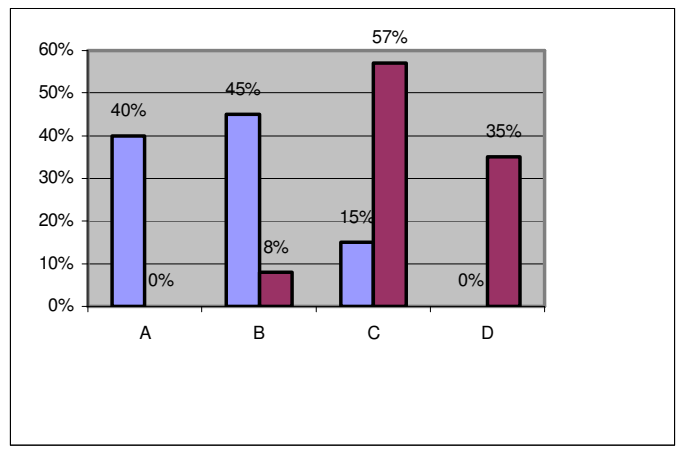

Figure 6a: Student Grade-Semester 1, 2001

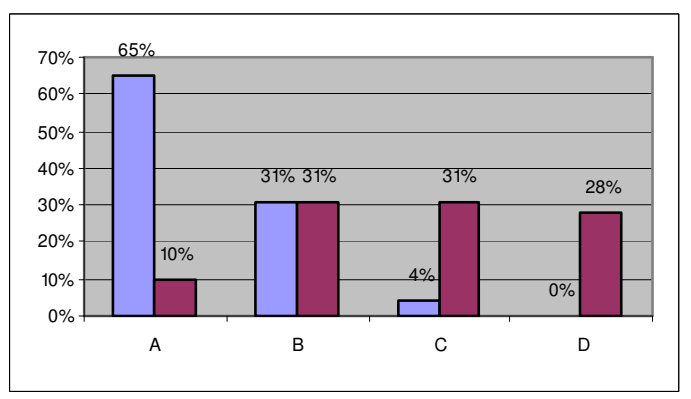

Figure 6c: Student Grade-Semester 1, 2002

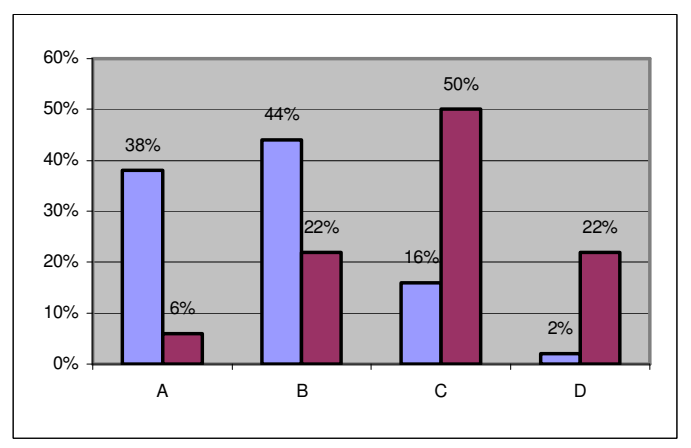

Figure 6b: Student Grade-Semester 2, 2001

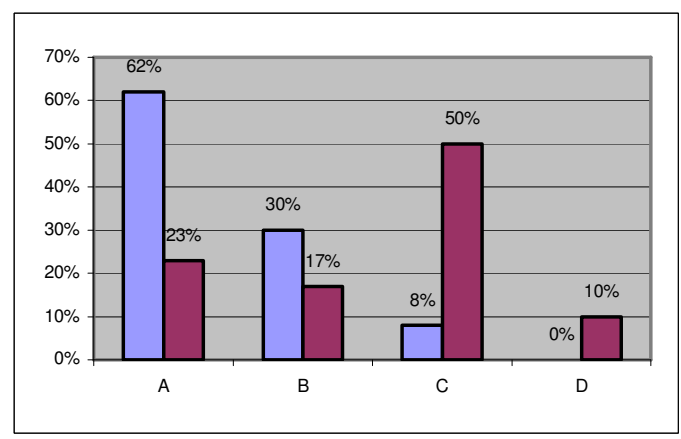

Figure 6d: Student Grade-Semester 2, 2002 

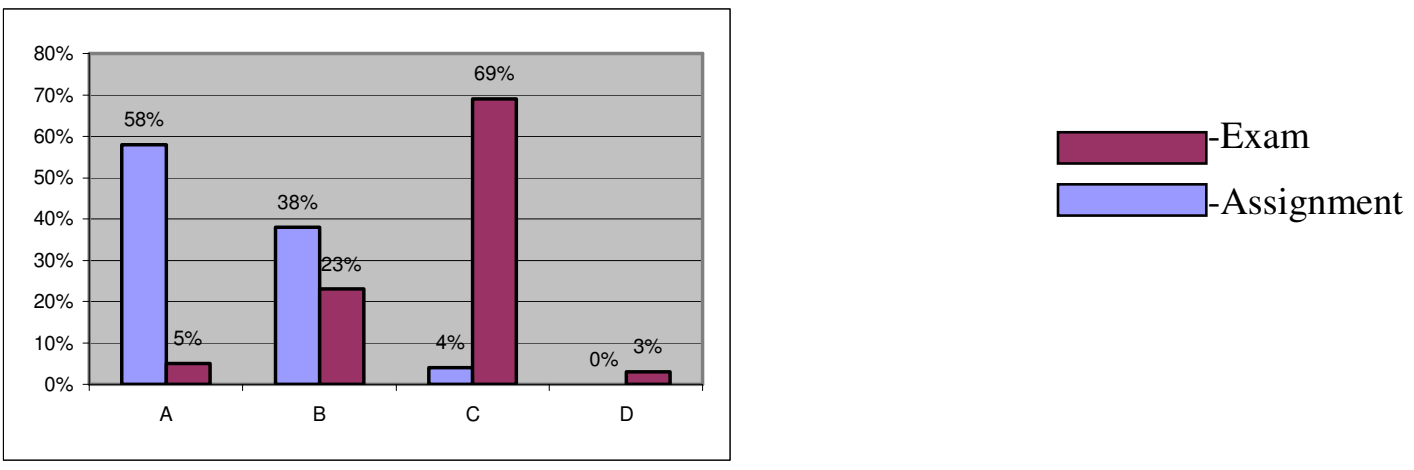

Figure 6e: Student Grade-Semester 1, 2003

The structure of the final written examination still remained the same, except for the inclusion of new topics. In order to improve student performance in the written exam, another assessment component was introduced. This was an online discussion forum and carried a weight of $10 \%$ towards the final marks. An in-house web learning management system called "Business Online" was used for the first time in semester 2, 2002 for running these discussions, which is currently being replaced by Blackboard. Blackboard is also used for posting assignments, course materials, making important announcements, sending e-mail notices to the class, and for other purposes that may arise.The topics for discussion included contemporary database technologies such as databases for electronic commerce and data warehousing. These concepts were also covered during the weekly lecture sessions. Students were required to research on each topic and contribute by posting their response individually to the forum. A response could be an answer to a question which is already posted or an example from their own or related experience. Each topic is given a duration of four weeks and there were three such topics in a semester. It was emphasized to students, that active participation in the discussions would provide substantial support in their preparation for the final exam and also help them to achieve higher grades. Though participation in discussions had a relatively small weightage $(10 \%)$, the emphasis on its relation to the final exam had a significant impact on the pass rates in the final exam. The reduction in the number of failures in the written exam can be seen from the results of semester 2 , 2002 and semester 1, 2003(Figures 6d and 6e). Though the overall pass rates have improved, the lower student grades in the final exam continue to be a matter of concern.

Other factors that might have affected the improvement in student performance include the changing cohort of both students and staff members involved in the educational process. In the New Zealand tertiary sector, it is a common practice for courses to be taught in teams, where one staff member (called the paper or the course co-ordinator) leads the team to discuss issues such as the action plan for the semester, assessment programme, moderation, teaching and learning strategies, and issues arising out of the previous semester's evaluation. Though valuable input and feedback was sought from different lecturers who taught on the course, the paper co-ordinator (who was also the main person involved in the restructuring process), remained the same and an attempt was made to ensure consistency in the educational process. It should also be noted that the student body of the Bachelor of Business degree consists of a relatively balanced mix of full time and part time students, balanced mix of gender, and students from a diverse range of cultural and ethnical backgrounds (Dougherty et al.2003). So, though both the cohort of students and staff members teaching the course have changed during the five semesters, they cannot be considered as significant factors which may have influenced the improvement in student performance. An external moderation conducted after the restructuring reported that the course achieved balance 
between theoretical/business usage and the learning objectives were well supported by the course assessments.

\section{Conclusion}

This paper described the restructuring of a data base management course for the Bachelor of Business (IT Major) programme at the Auckland University of Technology. The background and context of the course within the IT Major, the aim, content and the assessment structure, both before and after the restructuring process have been discussed. It was observed that both the course and student performance improved after the restructuring. Students completed the database project assessment with higher grades and appreciated its practical aspects. Students endorsed the inclusion of topics such as data warehousing and databases for electronic commerce as "very useful" and "relevant". However, students still perceive the final exam as "difficult" and it has been

an ongoing challenge to keep students motivated, especially when the majority of our students are employed while they study part-time.

\section{References}

AUT. (2001). Bachelor of business, Module Co-ordinators' handbook. Faculty of Business, Auckland University of Technology.

AUT. (2003). Faculty of business handbook. Auckland University of Technology.

Cappel, J.J. (2001-2002). Entry-level IS job skills: A survey of employers, Journal of Computer Information Systems, Winter 2001-2002, 76-82.

Clear, T. (1998). New Zealand Polytechnic business computing programmes graduate profiles. New Zealand Journal of Applied Computing and Information Technology, 2 (1), 118-130.

Clear, T. (2000). Practitioner education- Degrees of difference? ACM SIGCSE Bulletin, 32 (2), 11-12.

Clear, T. (2001). Graduate profile distinctions Bbus (IT) and BIT (Software Development). Auckland University of Technology.

Dougherty, J., Clear, T., Cooper, S., Dececchi, T., Richards, B., \& Wilusz, T. (2003). Information Technology Fluency in Practice. SIGCSE Bulletin, 35, 153 - 171.

Dietrich, S.W. \& Urban, S.D. (1996), Database theory in practice: Learning from cooperative group projects. ACM SIGCSE Bulletin, 28 (1), 112-116.

IS 2002 Model curriculum and guidelines for undergraduate programs in information systems (IS 2002). (2002).Retrieved September 8, 2003 from http://www.acm.org/education/is2002.pdf

Lee,D., E. Trauth, \& D.Farwell.(1995). Critical skills and knowledge requirements of IS professionals: A joint academic/industry investigation. MIS Quarterly, 19 (3), 313-340.

Saiedian, H. (1992). Guidelines for a practical approach to the database management systems course. Journal of Information Systems Education, 4 (1). Retrieved September 18th, 2002 from http://www.gise.org/JISE/Vol1-5/Guidelin.htm

Saiedian, H, \& Farhat, H. (1991). A team-oriented, project-intensive course. ACM SIGSCE Bulletin, 23 (1).

Springsteel,M., Robbert,M.A., \& Ricardo, C.M. (2000). The next decade of the database course: Three decades speak to the next. ACM SIGSCE Bulletin, 32 (1), 41-45.

Robbert, M.A. (2000). Enhancing the value of a project in the database course. ACM SIGSCE Bulletin, 32 (1), 41-45. 


\section{Biography}

Mali Senapathi is a Senior lecturer in the School of Computer and Information Sciences, Auckland University of Technology, New Zealand. She has been lecturing and developing course content in systems analysis and design and data base management systems since 1999. Her research interests include IT education and software usability. 